\title{
Meal-Time with a Socially Assistive Robot and Older Adults at a Long-term Care Facility
}

\author{
Derek McColl $^{1}$ and Goldie Nejat ${ }^{1,2}$ \\ ${ }^{1}$ Autonomous Systems and Biomechatronics Laboratory, \\ Department of Mechanical and Industrial Engineering, University \\ of Toronto, Toronto, ON, Canada \\ ${ }^{2}$ Toronto Rehabilitation Institute, Toronto, ON, Canada
}

As people get older, their ability to perform basic self-maintenance activities can be diminished due to the prevalence of cognitive and physical impairments or as a result of social isolation. The objective of our work is to design socially assistive robots capable of providing cognitive assistance, targeted engagement, and motivation to elderly individuals, in order to promote participation in self-maintenance activities of daily living. In this paper, we present the design and implementation of the expressive human-like robot, Brian 2.1, as a social motivator for the important activity of eating meals. An exploratory study was conducted at an elderly care facility with the robot and eight individuals, aged 82-93, to investigate user engagement and compliance during meal-time interactions with the robot along with overall acceptance and attitudes towards the robot. Results of the study show that the individuals were both engaged in the interactions and complied with the robot during two different meal-eating scenarios. A post-study robot acceptance questionnaire also determined that, in general, the participants enjoyed interacting with Brian 2.1 and had positive attitudes towards the robot for the intended activity.

Keywords: Human-robot interaction, socially assistive robot, meal-time assistant, older adults, user engagement and compliance, robot acceptance

\section{Introduction}

Proper nutrition is extremely important for the wellbeing of older adults, especially those who require physical or psychological assistance to eat. For example, more than $65 \%$ of nursing home residents experience unintentional weight-loss and under-nutrition due to cognitive disabilities (Sullivan \& Lipschitz, 1997). Furthermore, approximately $80 \%$ of elderly residents require oneon-one assistance during meal eating (Kayser-Jones, Schell, Porter, \& Paul, 1997; Pokrywka et al., 1997; Simmons, Osterweil, \& Schnelle, 2001). Nursing assistants in long-term care facilities and nursing homes currently provide meal-time assistance, which includes prompting or directly feeding individuals. However, this becomes challenging to implement as nursing assistants can become overwhelmed with providing individual care to so many people during a short meal-time in addition to performing other important tasks. Furthermore, due to the high turnover rates in nursing homes (Friedland, 2004), the consequences of an inadequate number of knowledgeable and well-trained staff during meal-times may include the negligence of the social dimensions of a meal-time, residents not receiving necessary assistance, or residents even being fed forcefully (Kayser-Jones \& Schell, 1997). Education and training are required for safely feeding long-term care residents (Kayser-Jones \& Schell, 1997).

\footnotetext{
Authors retain copyright and grant the Journal of Human-Robot Interaction right of first publication with the work simultaneously licensed under a Creative Commons Attribution License that allows others to share the work with an acknowledgement of the work's authorship and initial publication in this journal.
}

Journal of Human-Robot Interaction, Vol. 2, No. 1, 2013, Pages 152-171, DOI 10.5898/JHRI.2.1.McColl 
Frequently, caregivers, whose intentions are to merely help a person, take over an entire task such as eating rather than helping or encouraging the person to use their remaining abilities to do what they can for themselves. As a result, these individuals can feel frustrated and helpless, and hence, often lose the motivation and ability to take care of themselves as a result of emotional or environmental reasons rather than due to any cognitive impairment (Zeisel \& Raia, 2000). Moreover, if the residents do not consume an adequate amount of food during meal-times, serious health problems such as malnutrition may arise. Malnutrition is a serious problem amongst the elderly living in long-term care facilities as it contributes significantly to morbidity, decreased quality of life, and mortality (Chen, Schilling, \& Lyder, 2001). Namely, malnourished elderly patients have longer hospital stays, 2 to 20 times more health complications than healthy older adults, frequent re-admissions to hospitals, and delayed recovery times (Chen et al., 2001). Therefore, it is imperative to investigate new technological aids to effectively promote independent eating habits among elderly individuals living in nursing homes in order to address their needs during meal-times.

In this paper, we investigate the use of the human-like socially assistive robot Brian 2.1 (Figure 1), as a cognitive and social stimulation tool for older adults during meal-eating scenarios at a long-term care facility. In particular, we present an exploratory study used to investigate user engagement and compliance in the meal-eating task as well as user acceptance of the robot for the proposed interaction. Such studies are important to ensure that the development of socially assistive robots meet the needs of our growing elderly population.

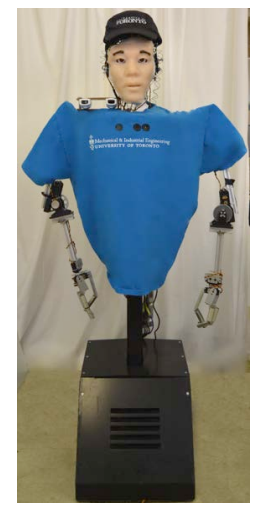

Figure 1. The socially assistive robot Brian 2.1.

\section{Robotic Meal-Time Assistants}

Currently, a number of robotic systems have been developed to aid the elderly and/or individuals with varying physical disabilities with the meal-eating activity. For example, in Soyama, Ishii, and Fukase (2003), the MySpoon robotic system was introduced as consisting of a desktop serial robot with 5 degrees of freedom (DOFs) controlled by a user through a hand or chin joystick or by a button. The end-effector of the arm had 1-DOF that held a spoon and a fork. The system consisted of a meal tray with four sections for food placement. The Handy 1 had also been developed to assist individuals with severe disabilities in tasks such as eating, washing, shaving, teeth brushing, and putting on make-up (Topping \& Smith, 1998). The system consisted of a robotic arm and plastic tray. A light scanning system was used to scan the food dish on the tray and a cup holder in order for a user to decide which food he/she would like to eat or if he/she would like a drink.

The MarO2 meal-assistance robotic arm has been developed for people suffering from tremors due to Parkinson's disease (Ohara, Yano, Horihata, Aoki, \& Nishimoto, 2009). The robotic arm allows for a person with tremors to move a spoon, connected to the robot, smoothly and safely by utilizing a tremor suppression system. In Koshizaki and Masuda (2010), a robotic arm was designed to feed Japanese disabled and elderly individuals using chopsticks. The MATS 5 DOF 
climbable robot presented in Balaguer et al. (2006) can move from different locations in an environment in order to assist in grooming, eating, dressing, and manipulating objects. For example in the eating scenario, the robot can be attached to a docking station on the wall in front of a person and directly feed the person. A user can control the robot using a personal digital assistant.

The MANUS robotic arm is intended to be mounted onto an electric wheelchair of an individual who lacks functioning in the arms and hands (Evers, Beugles, \& Peters, 2001). The robotic arm consists of six DOFs with a two-finger gripper and can be used to pick up various objects such as a cup of tea for the user to drink.

To date, research into the development of cognitive assistive devices specifically for the mealeating task is limited. To the authors' knowledge only the Erroneous Plan Recognition (EPR) system (Sim et al., 2010) can provide meal-time cognitive guidance. Environmental sensors are used by the EPR system to monitor a person and determine if he/she has executed a correct or erroneous action according to a pre-defined plan. Sensors include those for pressure placed on a chair to detect if a person has sat down, radio frequency identification antennas for object location on the table, and accelerometers placed on the person's arm for movement detection, such as if a person is bringing food from a plate to his/her mouth. If the person performed an erroneous action, the system provides audio and visual prompts to correct the action.

In our work, we propose the use of the embodied human-like socially assistive robot Brian 2.1 to provide cognitive assistance during meal eating through bidirectional interactions. The significance of using a human-like social robot lies in the ability to directly incorporate a person's existing capabilities to communicate naturally as well as his/her ability to understand these forms of communication. To date, several studies have emphasized the advantages of using embodied robots for engagement in health related activities (Kidd \& Breazeal, 2008; Powers, Kiesler, Fussell, \& Torrey, 2007; Tapus, Tapus, \& Mataric, 2009; Wainer, Feil-Seifer, Shell, \& Mataric, 2007). For example, in Kidd \& Breazeal (2008), use of a social robot was found to be effective for monitoring a person's diet and exercise. In particular, individuals that were provided with a robot over a computer interface or paper log used the robot for significantly longer periods of time to track their diet and exercise routine, while also creating a closer alliance with the robot than with the other systems. Tapus et al. (2009) emphasized the importance of using embodiment with cognitively impaired individuals to establish user engagement. In particular, a physical socially assistive robot and a simulation of the same robot on a computer screen were compared during a music game scenario. It was found that the participants consistently preferred the robot more than the computer interface and found it to be more engaging. It is interesting to note that during the study, some of the participants actually paid no attention to the computer interface at all.

Limited research has been conducted on the use and benefits of social robots as therapeutic aids in caring for elderly persons, with the majority of the emphasis being on pet-like robots, such as the seal-like robot, Paro (Inoue, Wada, \& Uehara, 2012), and the robotic dog, AIBO (Hamada et al., 2008), used in animal therapy scenarios that have shown improvements in mood, emotional control, memorization, and accommodation to society. A recent study of people's expectations of a robot companion indicated that a large proportion of participants were in favor of a robot communicating in a human-like manner (Dautenhahn et al., 2005). With respect to assistive robots this has shown to be true, for example, with the child-sized remote controlled humanoid robot KASPAR (Robins et al, 2010). This robot operated by caregivers has shown great potential as a social mediator for children with Autism Spectrum Disorders (ASD). The child-like robot Bandit has also been utilized to coach people in a wire puzzle stroke recovery exercise by providing instructions based on game performance (Wade, Parnandi, Mead, \& Mataric, 2011). The Pearl mobile robot with a cartoon-like face and touchscreen was used in a long-term care center to assist elderly individuals by guiding them to appointments and also by providing information such as weather forecasts (Montemerlo, Prieau, Roy, Thrun, \& Varma, 2002). Our research team is the first to develop a human-like socially assistive robot to provide cognitive guidance via social interactions during the imperative meal-eating activity. 


\section{Meal-Assistant Robot}

Several studies have investigated how caregiver behavior affects the meal-time experience of residents in long-term care facilities in order to promote independence and improve eating habits among elderly people (Hansson, 1978; Osborn \& Marshall, 1992; Schell \& Kayser-Jones, 1999). In particular, social interaction during meal-time has been found to play an important role in improving dietary intake; for example, in Schell and Kayser-Jones (1999), it was found that personal greetings, invitations to sit down, and/or comments about the appearance of the food were effective at engaging nursing home residents in the eating activity. Occasionally exchanging a few sentences on topics unrelated to food as well as displaying nonverbal behaviors such as smiles and laughter, were also effective at increasing engagement.

We have used the aforementioned criteria to design the cognitive intervention that Brian 2.1 provides individuals in order to better engage them in the meal-eating activity. The robot is situated directly facing the user in order to monitor the meal and provide one-on-one interactions. In particular, Brian 2.1 is a social motivator that provides personalized task assistance in order to encourage a person to consume contents of a meal via meal-related cues, encouragement, and orientating statements. To add a social element to the meal, Brian 2.1 uses natural verbal and nonverbal communication means (gestures, facial expressions, and vocal intonation), which include greeting the person by name, inviting him or her to sit down, and providing various mealrelated or non-meal-related jokes and positive statements. The robot is human-like from the waist up, its waist has two DOFs that allow the robot to turn left and right, and also to lean forward and back. The robot's two arms have four DOFs each: two DOFs at the shoulder, one at the elbow, and one at the wrist, which allow Brian 2.1 to point to different items on a meal tray. The robot's neck consists of 3 DOFs in order to display human-like head motions such as nodding and shaking. The robot's face is also actuated allowing it to display numerous facial expressions. For the mealeating activity, the robot displays happy (including smiling and laughing), neutral, and sad (frown and droopy eyes) facial expressions. The robot is also able to communicate verbally using speech and vocal intonation via a synthesized male voice that can mimic the aforementioned emotions through varying pitch and speed. Compared to the voice utilized for the neutral expression, a happy voice uses a higher pitch and faster speaking speed while a sad voice uses a lower pitch and slower speaking speed.

Brian 2.1 uses a unique meal-time monitoring system to track a person's meal consumption as well as eating/drinking actions during the meal-time interaction. Sensory information is acquired for the following: 1) meal consumption using a meal tray with embedded load cells, 2) tracking the 3D location and direction of motion of a utensil using infrared (IR) LEDs placed on the utensil, two Wii Remotes ${ }^{\mathrm{TM}}$, and the Kinect ${ }^{\mathrm{TM}}$ sensor, and 3) user state recognition using 2D images provided by the Kinect ${ }^{\mathrm{TM}}$ sensor to determine the user's visual focus of attention. The meal-time monitoring system is shown in Figure 2.

The meal-time monitoring system allows the robot to monitor the activity without requiring the user to wear any sensors, unlike other monitoring systems (Mataric, Eriksson, Feil-Seifer, \& Winstein, 2007; Rani, Sarkar, Smith, \& Kirby, 2004; Sim et al., 2010) and therefore promotes natural interactions with the robot. The meal tray can be calibrated with a variety of different dishes and cups allowing for the utilization of dishware already being used within long-term care facilities. Although a specialized utensil is required for tracking, it consists of low cost components including three infrared LEDs, a battery, and connection wires. During the design of the meal-monitoring sensory system, input from both healthcare scientists and healthcare professionals was obtained to optimize the system for its intended application and user group. 
McColl et al. Meal-Time with a Socially Assistive Robot

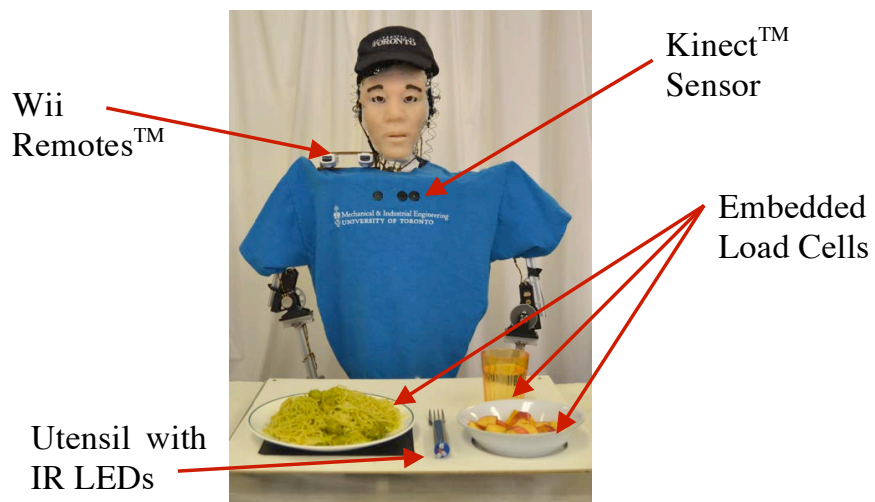

Figure 2. Brian 2.1 with meal-monitoring system.

\section{Meal Tray}

The main function of the meal tray-sensing platform is to monitor meal consumption via measuring the change in weight of food provided in a main dish, a side dish, and of a beverage provided in a cup. The meal tray consists of the following embedded sensors, as seen in Figure 3: 1) a DYMO M10 Scale consisting of load cells with a maximum weight capacity of $10 \mathrm{~kg}$ and a resolution of $2 \mathrm{~g}$ to measure the change in weight of the main dish; and 2) one pair of Phidgets shear micro load cells for the side dish and the beverage with each load cell having a $0.78 \mathrm{~kg}$ weight capacity and a resolution of $1 \mathrm{~g}$. The micro load cells are interfaced with a 4-input Phidgets bridge and the sensory information from each pair is averaged for both the side dish and the beverage. The sensing platform is calibrated based on the weight of an empty dish or cup only once prior to its use by implementing a simple calibration program. The raw sensor data is passed through a median filter to minimize noise. When the output of the median filter is more than twice the corresponding load cell sensor resolution, a change in weight is determined with respect to a specific meal item. In general, the meal tray sensing platform is used to monitor the following meal-time activities: 1) food has been picked up by the utensil (small decrease in weight), 2) the cup has been lifted up for drinking (decrease in cup weight to zero), 3) the beverage in the cup has been consumed (small decrease in cup weight), 4) a meal item has been finished (weight of meal item is equal to the weight of the empty dishware), and 5) food has not been eaten for an extended period of time (no weight change).

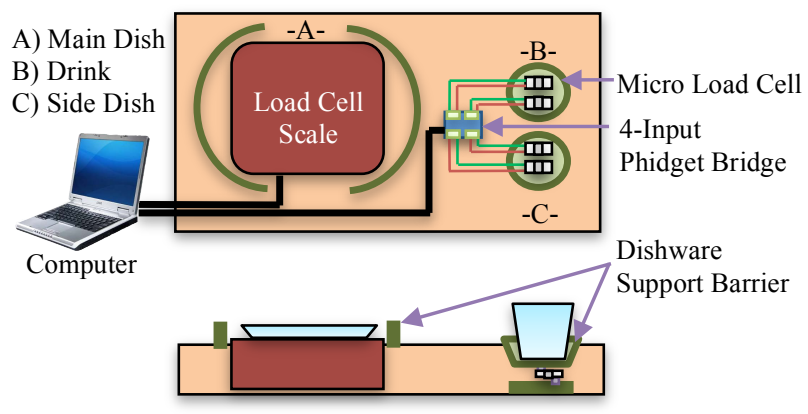

Figure 3. Meal Tray Sensory System 


\section{Utensil Tracking}

The main function of the utensil tracking system is to track the location and movement of the utensil during the meal in order to determine if the user is obtaining food from a dish and/or putting food in his or her mouth. The two Wii Remotes ${ }^{\mathrm{TM}}$ are utilized as stereoscopic infrared cameras to determine the 3D location of the utensil by monitoring the 3D position of infrared LEDs mounted on the utensil (Figure 4). The utensil tracking system also uses images provided by the Kinect ${ }^{\mathrm{TM}} 2 \mathrm{D}$ camera to determine the user's mouth location as the centroid of the bounding box around the mouth, which is found utilizing a Haar feature-based cascade classifier. The 3D pose of the mouth is then found within the Kinect ${ }^{\mathrm{TM}}$ depth image. Correspondence between the stereoscopic Wii Remotes ${ }^{\mathrm{TM}}$ and the Kinect ${ }^{\mathrm{TM}}$ sensor allows the utensil tracking system to determine the utensil's 3D pose relative to a user's mouth as well as to the meal tray. The 3D position of the utensil is determined to be at the tray or at the mouth. The utensil is at the tray when the infrared LEDs are located within one length of the utensil to the meal tray and it is considered to be at the mouth when the infrared LEDs are located within one utensil length of the mouth location. The location of the utensil is tracked in order to determine if it is moving toward the mouth or toward the tray.

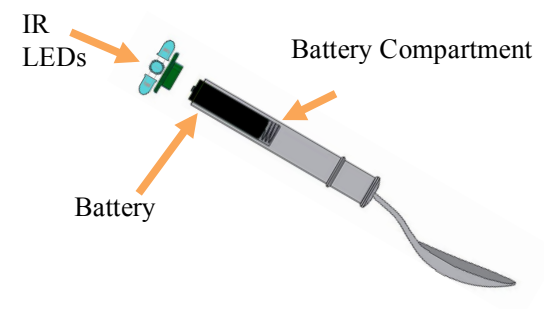

Figure 4. Utensil with infrared LEDs.

\section{User State}

The objective of the user state is to be able to recognize if a user is distracted in order to re-engage the person in the meal-eating task. The distracted user state is defined to occur when a user's face is not oriented toward the meal or the robot as detected utilizing the images from the Kinect ${ }^{\mathrm{TM}} 2 \mathrm{D}$ camera. In particular, visual focus of attention is tracked by determining the user's face orientation in the horizontal (looking left or right) direction. Facial orientation is detected by determining the location of the face, eyes, and nose using Haar feature-based cascade classifiers and then tracking the distances between the eyes and nose facial features of the user. When the face is pointed more than $45^{\circ}$ to the left or right of the robot and meal for an extended period of time, the user is determined to be distracted (as seen in Figure 5).

\section{Robot Behaviors for Meal-Eating Scenario}

Brian 2.1's assistive behaviors during meal eating are based on the objective of motivating a user to eat or drink the items on the meal tray while also promoting the social dimensions of eating. The robot focuses a person's attention to a particular dish or the beverage on the meal tray. The order in which a user is prompted to eat or drink is defined a priori based on a meal plan provided by the caregiver. The robot utilizes a finite-state acceptor (FSA) to determine which behaviors to implement. The FSA consists of a set of robot behavior states and triggering events, where the latter are provided by the meal-time monitoring system and are used to determine the appropriate robot behavior to display (Figure 6). With respect to the FSA presented in Figure 6, the meal plan chosen for our HRI study was to consume each meal item in the following order: main dish, side dish, and then beverage. The FSA can be adapted to utilize various sensory inputs to trigger behaviors based on consumption levels and/or time periods for each dish and the beverage, depending on the meal plan implemented. The FSA is divided into three main sections that are 


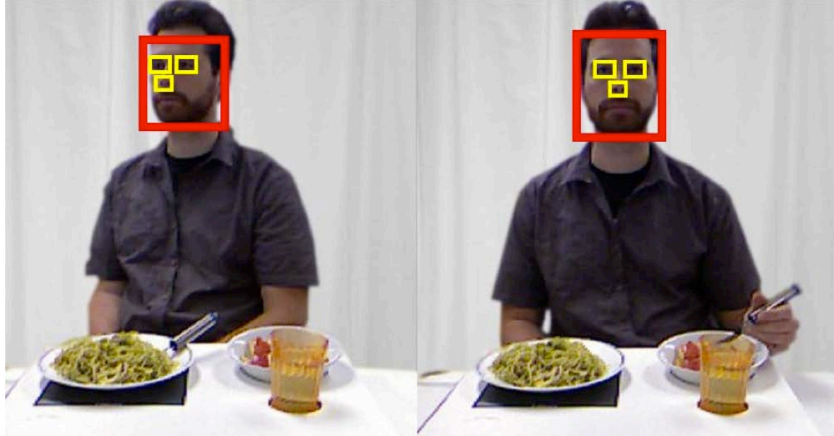

(a) face oriented to the right (b) face oriented toward robot

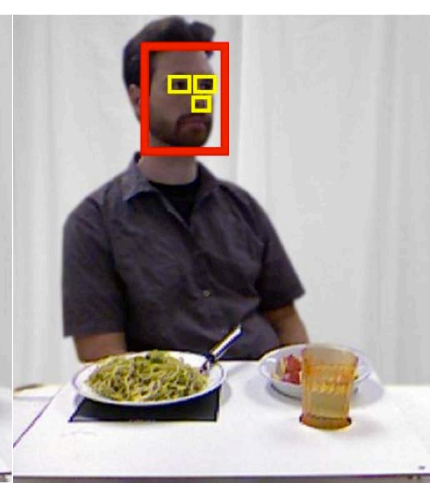

(c) face oriented to the left

Figure 5. Example face orientations with detected face, eyes, and nose identified for user distraction.

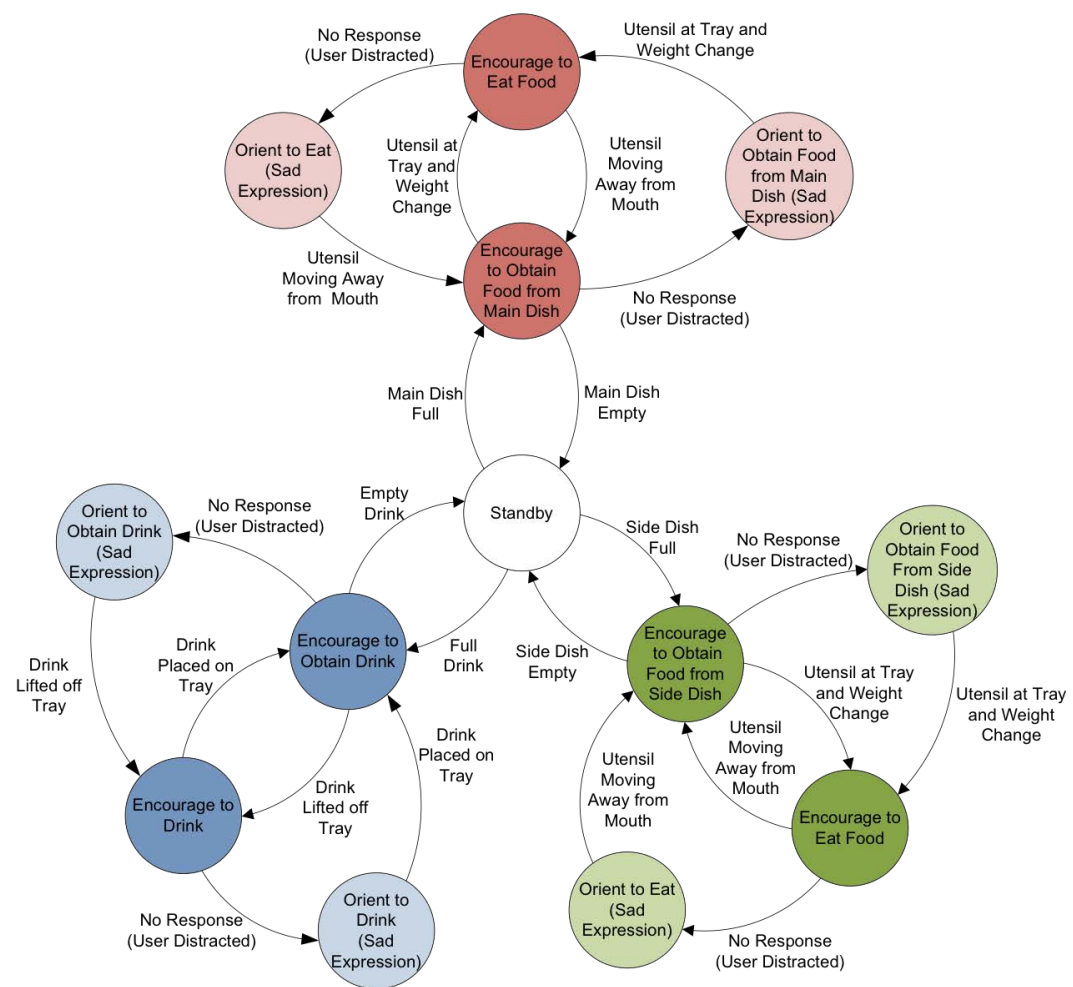

Figure 6. FSA diagram for the robot's assistive behaviors during the meal-eating activity.

each activated from the robot's standby state: 1) prompting behaviors to eat the main dish, 2) prompting behaviors to eat the side dish, and 3) prompting behaviors to drink the beverage. Each set of prompting behaviors is used to: 1) obtain food from a dish or lift a beverage, and 2) eat food or drink a beverage. These prompting behaviors comprise of two techniques to motivate a user to complete a given meal task: Encourage and Orient. Encouraging behaviors are positive reasoning tactics provided along with prompts to persuade the user to perform a meal task and are displayed by the robot in a happy emotional state (i.e., happy facial expression and tone of voice). Orienting behaviors designed to provide general awareness of the activity and the environment are displayed 
by the robot in a neutral emotional state. However, if the user is determined to be distracted from the meal and the robot for more than 10 seconds, the robot orients the user toward the meal in a sad emotional state. This time duration has been found to be appropriate for human interactions in social settings (Newman, Button, \& Cairns, 2010; Newman \& Cairns, 2006). Example robot behaviors are shown in Figure 7 and listed in Table 1.

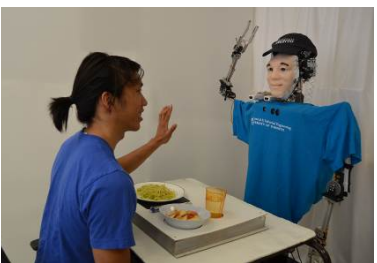

(a) Brian 2.1 greeting the user in a happy emotional state.

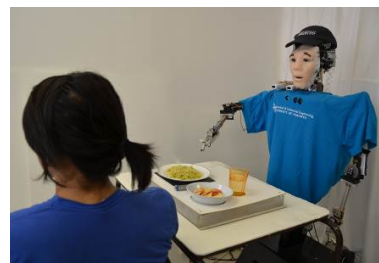

(b) Brian 2.1 orienting the user with a sad emotional state.

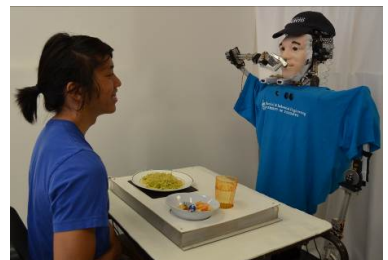

(c) Brian 2.1 telling a joke and laughing.

Figure 7. Example robot behaviors during a meal-eating activity.

Table 1. Example Robot Behaviors

\begin{tabular}{|c|c|}
\hline Behavior Type & Example Behavior \\
\hline Greeting & $\begin{array}{l}\text { "Hi! My name is Brian. You look very nice today. Please join me } \\
\text { for lunch." (waves while in a happy emotional state) }\end{array}$ \\
\hline $\begin{array}{l}\text { Encourage to obtain food from } \\
\text { the side dish }\end{array}$ & $\begin{array}{l}\text { "Yum! The side dish smells amazing. Why don't you pick up some } \\
\text { food?" (while in a happy emotional state) }\end{array}$ \\
\hline $\begin{array}{l}\text { Orient to obtain the main dish } \\
\text { (when user is distracted) }\end{array}$ & $\begin{array}{l}\text { "Your main dish is spaghetti located here on your tray." (while } \\
\text { pointing to the main dish on the tray in a sad emotional state) }\end{array}$ \\
\hline Encourage to eat food & $\begin{array}{l}\text { "That's a good helping of food you have there. Please take a bite!" } \\
\text { (while in a happy emotional state) }\end{array}$ \\
\hline Positive statements & $\begin{array}{l}\text { "What a beautiful day it is today; I am glad I get to spend some of it } \\
\text { with you." (while in a happy emotional state) }\end{array}$ \\
\hline Joke & $\begin{array}{l}\text { "What was the reporter doing at the ice-cream shop?" } \\
\text { "Getting the scoop!" (robot laughs and puts one hand in front of its } \\
\text { mouth) }\end{array}$ \\
\hline Valediction & $\begin{array}{l}\text { "I see that you have finished your meal. Thanks for letting me join } \\
\text { you for lunch today! Have a great day. Goodbye." (while waving } \\
\text { goodbye in a happy emotional state) }\end{array}$ \\
\hline
\end{tabular}

\section{HRI Study}

We conducted our study at a local elderly care facility to determine engagement and compliance of potential elderly users with Brian 2.1 during one-on-one meal-eating scenarios. We also investigated reactions, acceptance, and attitudes towards the robot as an assistive meal-time companion. Brian 2.1 was placed in a room at the facility and participants were invited to eat two meals with the robot.

\section{Participants}

Ethics approval was obtained prior to the commencement of the study. Written informed consent was also obtained from the participants prior to the first meal-eating activity with the robot. Inclusion criteria for the participants included that they be living in the nursing home or the supported living apartment, that they speak English with no significant hearing difficulties (to be able to understand the robot), and that they have mild to no cognitive impairment as determined by the Montreal Cognitive Assessment screening test (Nasreddine et al., 2005). These participants were chosen since they can provide detailed comments on their experience and the performance of the robot. Participants with moderate to severe cognitive impairment were excluded because of 
their inability to offer feedback on the robotic system. People with eating or swallowing difficulties were excluded for safety reasons. Our approach of using such a participant group for a preliminary study follows a similar procedure that is commonly used in the design of assistive robots (Grice, Lee, Evans, \& Kemp, 2012; Heerink, Kröse, Wielinga, \& Evers, 2006; Tsui \& Yanco, 2009; Ubeda, Azorin, Garcia, Sabater, \& Perez, 2012). The participants were recruited by making phone calls directly to care staff in these facilities and to some prospective participants or their nurses. A sample size of ten participants was chosen for this initial exploratory study. Eight out of the ten potential participants identified for the study were able to participate for the full duration of the study. The other two had scheduling conflicts and did not complete the study. In total, five females and three males ranging in ages from 82-93 ( $\mu=87$ and $\sigma=3.4)$ participated in the meal-eating activity. For this study, the participants ate a lunch-time meal with the robot on two separate occasions in one week.

\section{Methods}

Members of our research team introduced the robot to the participants and explained its functionality prior to commencement of the first meal-eating interaction with the robot. They told each participant that the robot would display both verbal and nonverbal communication in order to provide meal-time assistance; however, it would not be able to understand verbal dialogue spoken to it. During the interactions, one member of our team was present in an adjacent room that had a one-way mirror looking onto the interaction room, leaving the participant alone with the robot in the room. This researcher verified the behavior choices of the robot prior to their implementation during the interaction. A video camera was also placed in the room to record the interactions for analysis of engagement and compliance indicators. Figure 8 presents the interaction set-up as well as example interactions between Brian 2.1 and participants.
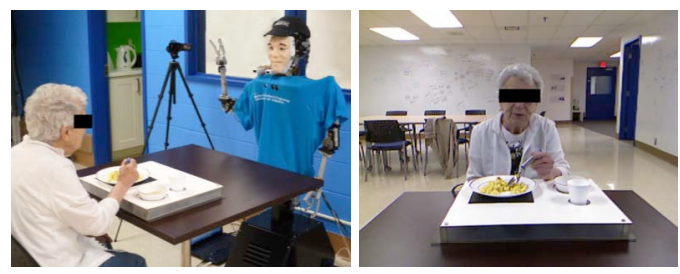

(a) Brian 2.1 encouraging a participant to eat the food on the main dish

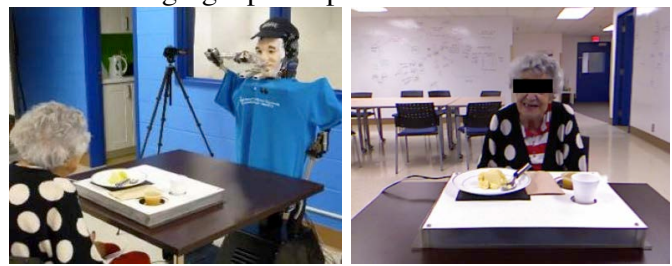

(b) Brian 2.1 telling a joke

Figure 8. Example meal-eating interactions.

The measured variables used for this HRI study were defined to be: (a) duration of interaction, (b) engagement in the interaction defined by visual focus of attention toward the robot or meal, manipulation of the utensil and cup, and verbal dialogue toward the robot, (c) compliance as defined by the participants' cooperative actions with respect to Brian 2.1's prompting behaviors that were performed within 2 minutes of the robot's prompt, and (d) acceptance and attitudes towards the robot as obtained from a post-study robot acceptance questionnaire.

A member of our research team performed the video analysis, which consisted of monitoring visual focus of attention, manipulation of the utensil and cup and verbal dialogue in order to determine user engagement, and monitoring of user actions with respect to the robot's prompts in order to determine user compliance. 
McColl et al. Meal-Time with a Socially Assistive Robot

The questionnaire we utilized herein included 10 constructs (33 questions) adapted from the Almere technology acceptance model (Heerink, Kröse, Evers, \& Wielinga, 2010), which was designed specifically to test acceptance of an assistive social agent with elderly users. The participants were asked to indicate their agreement with each statement on the questionnaire using a five point Likert scale (i.e., 5=strongly agree, 4=somewhat agree, 3=neutral, 2=somewhat disagree and $1=$ strongly disagree). The statements for the individual constructs are presented in Table 2. Descriptive statistics and Cronbach's alpha values for the constructs were formulated. In addition, the questionnaire also collected demographic information and the participants' previous technology experience with computers. Participants were also asked to identify the robot behavior characteristics they liked the most and which behaviors of the robot they thought were helpful.

Table 2. Constructs from the Almere model used in the Robot Acceptance Questionnaire

\begin{tabular}{|c|c|}
\hline Construct & Statement \\
\hline \multirow{4}{*}{$\begin{array}{l}\text { Anxiety } \\
(\text { ANX) }\end{array}$} & 1. If I should use the robot, I would be afraid to make mistakes with it \\
\hline & 2. If I should use the robot, I would be afraid to break something \\
\hline & 3. I find the robot scary \\
\hline & 4. I find the robot intimidating \\
\hline \multirow{2}{*}{$\begin{array}{c}\text { Attitude Towards Using the } \\
\text { Robot (ATT) }\end{array}$} & 5. I think it's a good idea to use the robot \\
\hline & 6. It's good to make use of the robot \\
\hline \multirow{3}{*}{$\begin{array}{l}\text { Intend to Use } \\
\text { (ITU) }\end{array}$} & 7. I think I'll use the robot again \\
\hline & 8. I am certain to use the robot again \\
\hline & 9. I'm planning to use the robot again \\
\hline \multirow{3}{*}{$\begin{array}{l}\text { Perceived Adaptability } \\
\text { (PAD) }\end{array}$} & 10. I think the robot can be adaptive to what I need \\
\hline & 11. I think the robot will only do what I need at that particular moment \\
\hline & 12. I think the robot will help me when I consider it necessary \\
\hline \multirow{5}{*}{$\begin{array}{l}\text { Perceived Enjoyment } \\
\text { (PENJ) }\end{array}$} & 13. I enjoy the robot talking to me \\
\hline & 14. I enjoy doing things with the robot \\
\hline & 15. I find the robot enjoyable \\
\hline & 16. I find the robot fascinating \\
\hline & 17. I find the robot boring \\
\hline \multirow{5}{*}{$\begin{array}{l}\text { Perceived Ease of Use } \\
\text { (PEOU) }\end{array}$} & 18. I think I will know quickly how to use the robot \\
\hline & 19. I find the robot easy to use \\
\hline & 20. I think I can use the robot without any help \\
\hline & 21. I think I can use the robot when there is someone around to help \\
\hline & 22. I think I can use the robot when I have a good manual \\
\hline \multirow{3}{*}{$\begin{array}{l}\text { Perceived Sociability } \\
\text { (PS) }\end{array}$} & 23. I consider the robot a pleasant conversational partner \\
\hline & 24. I find the robot pleasant to interact with \\
\hline & 25. I think the robot is nice \\
\hline \multirow{2}{*}{$\begin{array}{l}\text { Perceived Usefulness } \\
\text { (PU) }\end{array}$} & 25. I think the robot is useful to me \\
\hline & 26. I think the robot can help me with many things \\
\hline \multirow{5}{*}{$\begin{array}{l}\text { Social Presence } \\
\text { (SP) }\end{array}$} & 27. When interacting with the robot I felt like I'm talking to a real person \\
\hline & 28. It sometimes felt as if the robot was really looking at me \\
\hline & 29. I can imagine the robot to be a living creature \\
\hline & 30. I often think the robot is not a real person \\
\hline & 31. Sometimes the robot seems to have real feelings \\
\hline \multirow{2}{*}{$\begin{array}{l}\text { Trust } \\
\text { (TR) }\end{array}$} & 32. I would trust the robot if it gave me advice \\
\hline & 33. I would follow the advice the robot gives me \\
\hline
\end{tabular}

\section{Study Results}

The following presents the results of the HRI study with respect to system performance, user engagement and compliance, and acceptance of the meal-assistant robot and its characteristics. 
McColl et al. Meal-Time with a Socially Assistive Robot

\section{System Performance}

Recognition rates of the robot's sensory system during the interactions were determined with respect to meal-eating activities and user states. The results are presented in Table 3. 100\% recognition rates were obtained for the main dish and beverage states, and an $87 \%$ recognition rate was obtained for the side dish, with respect to a food item or the drink being picked up from the tray. The finished meal item state had $100 \%$ recognition rates for the main dish and beverage, and a $94 \%$ recognition rate for the side dish. For the state identified as no weight change in food item, the extended time interval was defined to be 2 minutes. The recognition rates for this state were $100 \%$ for both the main dish and the beverage, and $93 \%$ for the side dish. The utensil tracking system had recognition rates of $99 \%$ for detecting the utensil at the tray, $97 \%$ for detecting the utensil at the mouth, and $99 \%$ for detecting the utensil either moving toward the tray or toward the mouth. User state recognition rates were determined to be $98 \%$ for a distracted state and $96 \%$ for an engaged state with respect to the participants' visual focus of attention. Table 4 shows the robot's success rate at selecting and executing the appropriate assistive behaviors throughout the interactions. Brian 2.1 did not perform an orienting behavior during the interactions. This was due to the fact that the participants always manipulated a meal item within two minutes of an encouraging behavior (following the path in the FSA). Also because they never had a visual focus of attention away from both the robot and meal for more than 10 seconds, the robot did not need to execute an orienting behavior even when it detected this change in the user's state.

Table 3. Recognition Rates for Meal-Eating Activities and User States.

\begin{tabular}{|l|l|}
\hline Sensory System Output & Recognition Rate \\
\hline Meal Tray & $100 \%$ \\
\hline Weight Change Detected in Main Dish & $87 \%$ \\
\hline Weight Change Detected in Side Dish & $100 \%$ \\
\hline Weight Change Detected in Drink & $100 \%$ \\
\hline Beverage Lifted From Tray & $100 \%$ \\
\hline Main Dish Finished & $94 \%$ \\
\hline Side Dish Finished & $100 \%$ \\
\hline Beverage Finished & $100 \%$ \\
\hline No Weight Change in Main Dish for Extended Period & $93 \%$ \\
\hline No Weight Change in Side Dish for Extended Period & $100 \%$ \\
\hline No Weight Change in Beverage for Extended Period & \\
\hline Utensil Tracking & $99 \%$ \\
\hline Utensil at Tray & $97 \%$ \\
\hline Utensil at Mouth & $99 \%$ \\
\hline Utensil Moving Toward the Tray & $99 \%$ \\
\hline Utensil Moving Toward the Mouth & \\
\hline User State & $98 \%$ \\
\hline User Distracted & $96 \%$ \\
\hline User Engaged & \\
\hline
\end{tabular}

Table 4. Robot Behavior Selection and Execution Results.

\begin{tabular}{|c|c|c|}
\hline Activity State & Expected Robot Behavior & $\begin{array}{c}\text { Success } \\
\text { Rate }\end{array}$ \\
\hline Start of meal interaction & Greeting & $100 \%$ \\
\hline Utensil at tray and main dish not consumed & Encourage to obtain food from the main dish & $100 \%$ \\
\hline Utensil at tray and side dish not consumed & Encourage to obtain food from the side dish & $100 \%$ \\
\hline Utensil at tray and drink not consumed & Encourage to obtain drink & $100 \%$ \\
\hline Utensil at tray and weight change at main dish & Encourage to eat food & $100 \%$ \\
\hline Utensil at tray and weight change at side dish & Encourage to eat food & $87 \%$ \\
\hline Drink lifted from tray & Encourage to drink & $100 \%$ \\
\hline All meal items completed & Valediction & $100 \%$ \\
\hline
\end{tabular}


McColl et al. Meal-Time with a Socially Assistive Robot

Table 5. Engagement Indicators

\begin{tabular}{|c|c|c|c|c|}
\hline Participant & $\begin{array}{c}\text { Total } \\
\text { Interaction } \\
\text { Time } \\
\text { (Minutes) }\end{array}$ & $\begin{array}{c}\text { Visual Focus of } \\
\text { Attention Toward the } \\
\text { Robot or Meal } \\
\text { (Percentage of Total } \\
\text { Interaction Time) }\end{array}$ & $\begin{array}{c}\text { Time Spent } \\
\text { Manipulating Meal } \\
\text { Items (Percentage of } \\
\text { Total Interaction } \\
\text { Time) }\end{array}$ & $\begin{array}{c}\text { Total Number of } \\
\text { Utterances Toward } \\
\text { Robot }\end{array}$ \\
\hline P1 & 55.20 & $100 \%$ & $71 \%$ & 86 \\
\hline P2 & 9.93 & $95 \%$ & $84 \%$ & 20 \\
\hline P3 & 12.35 & $97 \%$ & $85 \%$ & 24 \\
\hline P4 & 13.47 & $99 \%$ & $42 \%$ & 23 \\
\hline P5 & 13.77 & $99 \%$ & $64 \%$ & 34 \\
\hline P6 & 22.00 & $98 \%$ & $78 \%$ & 21 \\
\hline P7 & 10.88 & $98 \%$ & $81 \%$ & 51 \\
\hline P8 & 17.1 & $96 \%$ & $43 \%$ & $\mathbf{3 6}$ \\
\hline Average & $\mathbf{1 9 . 3 4}$ & $\mathbf{9 8 \%}$ & $\mathbf{6 9 \%}$ & 30 \\
\hline
\end{tabular}

\section{Engagement}

The results for each of the engagement parameters and the total engagement time for each participant are provided in Table 5. During the two meals, it was found that participants had visual focus of attention either toward the robot or meal for an average of $98 \%$ of the total interaction time. The participants spent the remaining $2 \%$ of interaction time looking around their environment. Sixty-nine percent of the total interaction time was spent manipulating meal items. On average it was found that the participants spoke 36 utterances to the robot during the two meals, even though they were initially told that the robot was not able to understand verbal communication. From Table 5, it can be seen that longer interaction times also resulted in more social interactions with the robot. In Table 6, the distribution of the utterances of the participants with respect to the robot's behaviors are presented. The majority of utterances were stated after the robot provided positive statements followed by the robot encouraging the participants to eat. It can also be seen that participants stated utterances to Brian 2.1 even when the robot was not displaying any behavior.

\section{Compliance}

Table 7 shows the total number of prompts provided by Brian 2.1 during the interactions with each participant and participant compliance with these prompts. Only one participant had a compliance rate of more than one standard deviation $(\sigma=9.1 \%)$ from the overall mean $(\mu=87 \%)$; P2 at $67 \%$. Therefore, the remaining seven participants complied with, on average, $90 \%$ of the robot's prompting behaviors. The low rating of compliance (67\%) for P2 is due to the fact that this participant did not like the taste of the food in her main dish during her first meal with the robot, which became apparent when she told this to our research team after she finished her interaction. When the robot prompted her to eat her main dish, she would instead eat the side dish as she liked the taste of that dish.

\section{Acceptance and Attitude Towards the Robot}

The box plots for the descriptive statistics of the constructs of the adapted Almere technology acceptance model are presented in Figure 9, with the scores on negative statements (such as for Anxiety) having reverse scores. In order to verify inter-reliability between statements for constructs which have multiple statements, Cronbach's alpha values were determined for each of these constructs. The values are also presented in Figure 9. In general, alpha values of at least 0.5 are considered acceptable for such short instruments (Kehoe, 1995). All of the constructs had acceptable alpha values of 0.5 or greater except for PU. For the PU construct, the low alpha value could be a result of having only two questions for this construct. 
McColl et al. Meal-Time with a Socially Assistive Robot

Table 6. Distribution of Participant Utterances With Respect to Robot Behavior

\begin{tabular}{|c|c|c|c|}
\hline $\begin{array}{c}\text { Robot } \\
\text { Behavior Type }\end{array}$ & Example Robot Behavior & $\begin{array}{c}\text { Number of } \\
\text { Participant } \\
\text { Utterances } \\
\text { Toward Robot }\end{array}$ & $\begin{array}{c}\text { Example Participant } \\
\text { Utterances Toward } \\
\text { Robot }\end{array}$ \\
\hline Greeting & $\begin{array}{c}\text { "Hello again! Today's menu includes } \\
\text { pasta, apple sauce, and juice. Please have } \\
\text { lunch with me." (waves while in a happy } \\
\text { emotional state) }\end{array}$ & 25 & $\begin{array}{c}\text { "Thank you. How are you? } \\
\text { I have missed you since } \\
\text { last week." }\end{array}$ \\
\hline $\begin{array}{c}\text { Encourage to } \\
\text { obtain main dish }\end{array}$ & $\begin{array}{l}\text { "The main dish looks delicious. You } \\
\text { should pick up some food with your } \\
\text { spoon."(while in a happy emotional state) }\end{array}$ & 26 & $\begin{array}{l}\text { "I will. Thank you very } \\
\text { much." }\end{array}$ \\
\hline $\begin{array}{l}\text { Encourage to } \\
\text { obtain side dish }\end{array}$ & $\begin{array}{c}\text { "The side dish looks very tasty. Why } \\
\text { don't you try some?" (while in a happy } \\
\text { emotional state) }\end{array}$ & 12 & $\begin{array}{c}\text { "It's too bad you can't } \\
\text { have some, it's pretty good } \\
\text { Brian." }\end{array}$ \\
\hline $\begin{array}{l}\text { Encourage to } \\
\text { obtain drink }\end{array}$ & $\begin{array}{c}\text { "You should try some of your beverage. It } \\
\text { looks refreshing." (while in a happy } \\
\text { emotional state) }\end{array}$ & 32 & $\begin{array}{c}\text { "Yes I am going to have } \\
\text { some." }\end{array}$ \\
\hline Encourage to eat & $\begin{array}{l}\text { "What you have on your spoon looks like } \\
\text { it will taste really good. Please take a } \\
\text { bite." (while in a happy emotional state) }\end{array}$ & 33 & $\begin{array}{c}\text { "I must admit it is different } \\
\text { but very tasty." }\end{array}$ \\
\hline $\begin{array}{l}\text { Encourage to } \\
\text { drink }\end{array}$ & $\begin{array}{c}\text { "The drink in your hand looks delightful. } \\
\text { Why don't you take a sip?" (while in a } \\
\text { happy emotional state) }\end{array}$ & 5 & $\begin{array}{l}\text { "You know what they gave } \\
\text { me Brian? I think that they } \\
\text { gave me some cranberry } \\
\text { juice." }\end{array}$ \\
\hline $\begin{array}{c}\text { Positive } \\
\text { statements }\end{array}$ & $\begin{array}{c}\text { "I really like your company; I hope we } \\
\text { can do this more often." (while in a happy } \\
\text { emotional state) }\end{array}$ & 82 & $\begin{array}{l}\text { "I hope so. I hope I see } \\
\text { you again. And see I never } \\
\text { forgot your name and I } \\
\text { was looking forward to } \\
\text { meeting you again." }\end{array}$ \\
\hline Joke & $\begin{array}{l}\text { "Why did the cookie go to the doctor?" } \\
\text { "She was feeling crummy!" (robot laughs } \\
\text { and puts one hand in front of its mouth) }\end{array}$ & 18 & $\begin{array}{c}\text { (chuckles) "Very funny } \\
\text { Brian." }\end{array}$ \\
\hline Valediction & $\begin{array}{c}\text { "Excellent, you have finished your meal. } \\
\text { Thanks for spending your lunch with me. } \\
\text { (while waving goodbye in a happy } \\
\text { emotional state) }\end{array}$ & 28 & $\begin{array}{c}\text { "I hope to see you again in } \\
\text { the future." }\end{array}$ \\
\hline $\begin{array}{l}\text { No-robot } \\
\text { behavior }\end{array}$ & Not Applicable & 28 & $\begin{array}{l}\text { Participant commented to } \\
\text { Brian on his late arrival to } \\
\text { the experiment: "Sorry I } \\
\text { was late Brian." } \\
\text { After participant took a } \\
\text { bite of the main dish, he } \\
\text { asked Brian: } \\
\text { "Have you had your lunch } \\
\text { yet?" } \\
\text { Participant asked Brian } \\
\text { about interactions with } \\
\text { other people: } \\
\text { "Have you seen anyone } \\
\text { else today?" }\end{array}$ \\
\hline
\end{tabular}


McColl et al. Meal-Time with a Socially Assistive Robot

Table 7. Compliance Indicators

\begin{tabular}{|c|c|c|}
\hline Participant & $\begin{array}{c}\text { Total Number of } \\
\text { Prompts by Robot }\end{array}$ & $\begin{array}{c}\text { Prompts Followed by } \\
\text { Participant (Percentage of } \\
\text { Total Number of Prompts) }\end{array}$ \\
\hline P1 & 28 & $96 \%$ \\
\hline P2 & 9 & $67 \%$ \\
\hline P3 & 11 & $91 \%$ \\
\hline P4 & 13 & $85 \%$ \\
\hline P5 & 12 & $83 \%$ \\
\hline P6 & 18 & $94 \%$ \\
\hline P7 & 10 & $90 \%$ \\
\hline P8 & 18 & $89 \%$ \\
\hline Average & $\mathbf{1 5}$ & $\mathbf{8 7 \%}$ \\
\hline
\end{tabular}

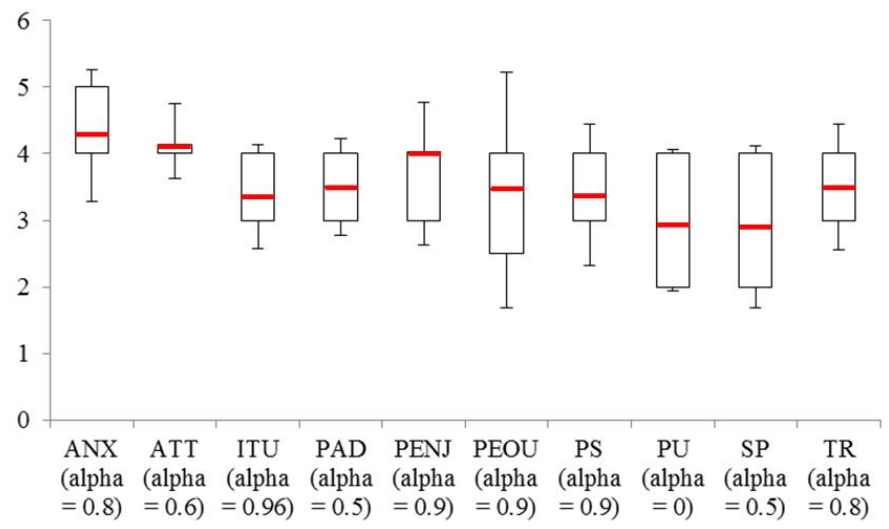

Figure 9. Box plots showing first and third quartiles with standard deviation from the mean (red) for each construct.

The questionnaire results show that in general, the participants had a positive attitude towards Brian 2.1 and they found interactions with the robot to be enjoyable. Furthermore, they had little anxiety towards interacting with the robot.

There was a bit of confusion with some of the participants regarding the intent to use the robot in the future that may have resulted in more neutral responses for this particular construct. Since the questionnaire was administered after the second and final meal of the study, the participants knew the study was over and their answers reflected this. Namely, even though the research team mentioned that the questions for intent to use were with respect to the robot being available to them beyond the study, the majority of participants mentioned that the study was over so they would not be able to interact with Brian 2.1 again. For future studies, we will revise the wording for these questions to better reflect this point. The neutral ratings for the participant's perceived sociability of Brian 2.1 may be due to the robot's inability to respond to the verbal dialogue that was spoken to it during the interactions. For example, some participants asked the robot questions such as "When are you going to eat?" or "What about your meal?" What is also interesting to note is that although the participants' scores for trusting the robot were somewhat neutral, they still complied with the robot's prompting behaviors.

\section{Most-Liked and Helpful Characteristics of Brian 2.1}

As we aimed to design Brian 2.1 to resemble a human in both communication capabilities and behaviors, we asked individuals to choose from a list of characteristics, the characteristics of the robot that they most liked and found most helpful in order to investigate if there was any 
preference with respect to the robot's human-like attributes. Table 8 summarizes the responses for the most-liked characteristics. Eighty-eight percent of the participants liked the robot's human-like voice. Companionship the robot provided was the second most-liked characteristic at $75 \%$, and the ability of the robot to express different emotions through facial expressions and different tones of voice was the third most-liked robot characteristic with $63 \%$. The robot's life-like appearance and demeanor was liked by half of the participants. These results are consistent with feedback from the participants; six of the eight participants mentioned that the robot's voice was clear and helpful, while three participants explicitly thanked the robot for providing companionship during the meals by saying "I thank you for your company," "It is nice talking to you, thank you for keeping me company," and "You are also very good company."

Table 8. Most-Liked Characteristics of Brian 2.1 during the Meal-Eating Activity

\begin{tabular}{|l|c|}
\hline \multicolumn{1}{|c|}{ Robot Characteristics } & $\begin{array}{c}\text { Percentage of } \\
\text { Participants }\end{array}$ \\
\hline The robot's human-like voice & $88 \%$ \\
\hline The companionship the robot provides by just being there & $75 \%$ \\
\hline $\begin{array}{l}\text { The robot expressing different emotions through facial } \\
\text { expressions and different tones of voice }\end{array}$ & $63 \%$ \\
\hline The robot's life-like appearance and demeanor & $50 \%$ \\
\hline
\end{tabular}

With respect to the most helpful characteristics of Brian 2.1, all eight participants stated that the robot providing encouraging behaviors during the meal was the most helpful. Twenty-five percent of the participants also found the greeting behavior helpful because during this time the robot told them the menu of the meal they were going to eat.

A few participants elaborated on their responses with respect to the robot's characteristics. For example, one comment regarding the robot that was shared by three participants was with respect to gaze direction; they stated as a future improvement, that Brian 2.1's eyes should move frequently during the interactions (for example, from the user to the meal tray), as currently the robot's eyes are not actively controlled and the head is only actuated.

\section{Discussion}

The main errors in system performance were due to the load cells used for the side dish not detecting when three participants occasionally took very small amounts of the food from this dish (in all cases it was apple sauce). This also resulted in the robot failing to select and execute the "encourage to eat" behavior at these instances. In order to address this issue, we will need to consider increasing the sensitivity of the sensory system or combining visual food detection algorithms with the weight detection algorithms. The state recognition rates for the main dish and beverage were much higher at $100 \%$. The utensil tracking system also had high recognition rates. There were only two occurrences when the infrared LEDs were occluded from the Wii Remotes ${ }^{\mathrm{TM}}$ due to the orientation of the utensil. The errors in the user state detection occurred due to the Haar classifiers not identifying the correct location of a single participant's eyes during three occurrences and hence, the correct head orientation due to partial occlusion of the eyes by the frame of her glasses. It is also noted that with respect to the meal-monitoring sensory system, no participants mentioned any issues with using the meal tray or utensil nor did they have any difficulties using these components during the study.

Engagement is an important factor when designing robots intended to be used in everyday activities. Using the engagement indicators, we were able to identify that Brian 2.1 was able to engage these eight elderly participants in the meal-eating activity during the two meals. We will need to conduct more long-term studies to determine if this level of engagement can be sustained over a longer interaction time. In future larger clinical studies, it may also be possible to determine if any relationships exist between the number of prompts the robot performs and user engagement and compliance. In general, there have only been a handful of studies that have directly measured engagement levels of older adults during HRI scenarios with socially assistive robots (Libin \& Cohen-Mansfield, 2004; Taggart, Turkle, \& Kidd, 2005). For example, in Taggart et al. (2005), a 
study was presented with the seal-like robot, Paro, in a nursing home environment. Twelve out of eighteen older adults participating in the study actively chose to engage with the robot by speaking to it, touching it, and asking about it. This occurred with minimal observable change over time. In Libin and Cohen-Mansfield (2004), attention, attitude, intensity of manipulation, and duration of engagement with both a robotic cat and a plush toy cat were investigated with residents diagnosed with dementia living in a nursing home. It was found that there was no statistical significance for the engagement parameters between the robotic and toy cats.

Compliance with the robot's social behaviors is very important in the meal-eating activity in order to ensure that individuals actually eat their food and obtain proper nutrients. The average compliance rate of $87 \%$ shows the potential use of a socially assistive robot for this daily-living activity. Other studies have also investigated compliance with socially interacting robots. For example, in Mataric et al. (2007), a study was presented with a Pioneer mobile robot used to prompt and engage patients in different exercises for stroke rehabilitation. The study found that participant compliance was much higher with the robot than with the no-robot or prompting condition. In Fasola and Mataric (2012), high user compliance was determined for elderly participants with respect to encouraging behaviors of a child-like social robot during arm exercises. The behaviors included demonstrating the exercises and verbally commenting on participant performance.

The results of the robot acceptance questionnaire demonstrated that participants had positive attitudes towards the robot and enjoyed interacting with it during the meal-eating activity. Also, in general, the older adults felt little anxiety towards the robot, even though it was a new system. This feedback from the elderly participants further motivates the use of such social robots with this vulnerable population. These responses are similar to the positive responses obtained for the same constructs by Heerink, Kröse, Evers, \& Wielinga (2009) for their study with elderly participants and the iCat robot. In that particular study, participants interacted one-on-one with the iCat robot using a touchscreen to get the weather forecast, hear a joke, or preview a television program.

Brian 2.1's human-like voice was the most-liked characteristic of the robot and the robot's encouraging behaviors were identified to be the most helpful by our participants. Similar findings were also reported in Kuo et al. (2009) for the Charles robot. Namely, in Kuo et al. (2009), the robotic voice was the highest-rated feature of the robot for the older adult group; however, some people in both the older and middle-aged groups found the voice too robotic or monotone. Older participants also rated the robot's instructions as the second highest-rated feature. In Zhang et al. (2010), a repeated measures study in a simulated patient room was conducted to determine the effects of three robot features, which included facial configuration, voice messaging, and interactivity. The robot interacted with elderly participants by providing them with medication. The most-liked feature was found to be the voice.

From direct observations of the interactions, we also found that all eight participants stated at least one positive utterance to the robot during the meal activity with respect to its presence during the meal, while three participants stated two or more positive utterances during the course of the activity. These included statements such as, "It is very nice to be here with you," "I am glad to spend some time with you," and "I look forward to seeing you again." With respect to nonverbal communication toward the robot, when Brian 2.1 smiled or told jokes, five of the participants smiled back at the robot or laughed at its jokes while making eye contact.

Some caregivers also provided some high-level comments regarding the use of the robot for the intended activity. Namely, they mentioned that a meal-assistant robot would not get impatient with slow eaters and would allow caregivers to concentrate on individuals requiring more urgent assistance.

Although the researchers did not include any deliberate distractors for this study, the room containing the robot and participant was part of the long-term care facility and staff occasionally walked in and out of the room as needed. However, the participants were not distracted by these people. The study set-up allowed us to obtain data and feedback regarding the performance and 
use of the system prior to implementing future larger long-term studies in dining halls of longterm care facilities.

\section{Conclusion}

Our work focuses on designing and implementing the human-like socially assistive robot Brian 2.1 to improve independent eating habits of elderly individuals and enhance their meal-time experience during the important self-maintenance activity of eating. In particular, this paper presents an exploratory study with Brian 2.1 interacting with eight older adults at an elderly care facility during two lunch-time meals. The results of the study show that the individuals were both engaged in the interaction and complied with the robot. Results of a post-study robot acceptance questionnaire showed that the participants, in general, had positive attitudes towards Brian 2.1 and found interaction with the robot to be enjoyable. The majority of participants especially liked the robot's human-like voice and the companionship the robot provided by just being there, and all the participants found its encouraging behaviors helpful. The results of this exploratory study are promising and motivate conducting larger long-term studies with the Brian 2.1 robot in order to evaluate the effectiveness of the robot as a social motivator during the meal-eating activity for the elderly population and investigate participants' perceptions of the robotic system in comparison to a no-robot condition or to a human caregiver condition. Our future work also includes determining the best integration procedure for robot deployment in long-term care facilities to ensure the safety of potential users.

\section{Acknowledgments}

The authors would like to thank Jeff McCarthy and Bianca Stern for assisting with this study. This research has been funded in part by the Ontario Graduate Scholarship (OGS) and the Natural Sciences and Engineering Council of Canada (NSERC).

\section{References}

Balaguer, C., Gimenez, A., Huete, A. J., Sabatini, A. M., Topping, M. \& Bolmsjo, G. (2006). The MATS robot: Service climbing robot for personal assistance. IEEE Robotics \& Automation Magazine, 13(1), 51- 58. http://dx.doi.org/10.1109/MRA.2006.1598053

Chen, C. C., Schilling, L. S. \& Lyder, C. H. (2001). A concept analysis of malnutrition in the elderly. Journal of Advanced Nursing, 36(1), 131-142. http://dx.doi.org/10.1046/j.13652648.2001.01950.x

Dautenhahn, K., Woods, S., Kaouri, C., Walters, M. L., Koay, K. L. \& Werry, I. (2005). Proceedings from the IEEE/RSJ International Conference on Intelligent Robots and Systems: What is a robot companion - Friend, assistant or butler? (pp. 1192-1197). http://dx.doi.org/10.1109/IROS.2005.1545189

Evers, H. G., Beugels E. \& Peters G. (2001). Proceedings from the International Conference on Rehabilitation Robotics (ICORR): MANUS: Towards a new decade. (pp. 155-161). Evry, France.

Fasola, J. \& Mataric, M. J. (2012). Using socially assistive human-robot interaction to motivate physical exercise for older adults. Proceedings of the IEEE, 100(8), 2512-2526. http://dx.doi.org/10.1109/JPROC.2012.2200539

Friedland, R. B. (2004). Caregivers and long-term care needs: Will public policy meet the challenge? Georgetown University Long-Term Care Financing Project, Issue Brief. Washington, DC: Georgetown University Press.

Grice, P. M., Lee, A., Evans, H., \& Kemp, C. C. (2012). Proceedings from the IEEE International Symposium on Robot and Human Interactive Communication (RO-MAN 2012): The wouse: A 
McColl et al. Meal-Time with a Socially Assistive Robot

wearable wince detector to stop assistive robots. (pp. 165-172). http://dx.doi.org/10.1109/ROMAN.2012.6343748

Hamada, T., Okubo, H., Inoue, K., Maruyama, J., Onari, H., Kagawa, Y., \& Hashimoto, T. (2008). Proceedings from the IEEE International Symposium on Robot and Human Interactive Communication: Robot therapy as for recreation for elderly people with dementia - Game recreation using a pet-type robot. (pp. 174-179). http://dx.doi.org/10.1109/ROMAN.2008.4600662

Hansson, R. G. (1978). Considering social nutrition in assessing geriatric nutrition. Geriatrics, $33(3), 49-51$.

Heerink, M., Kröse, B., Wielinga, B. J., \& Evers, V. (2006). Studying the acceptance of a robotic agent by elderly users. International Journal of Assistive Robotics and Mechatronics, 7(3), 33-43.

Heerink, M., Kröse, B., Evers, V .\& Wielinga, B. (2009). Proceedings from the IEEE International Symposium on Robot and Human Interactive Communication: Measuring acceptance of an assistive social robot: A suggested toolkit. (pp. 528-533). http://dx.doi.org/0.1109/ROMAN.2009.5326320

Heerink, M., Kröse, B., Evers, V. \& Wielinga, B. (2010). Assessing acceptance of assistive social agent technology by older adults: The Almere Model. International Journal of Social Robotics, 2(4), 361-375. http://dx.roi.org/10.1007/s12369-010-0068-5

Inoue, K., Wada, K., \& Uehara, R. (2012). Proceedings from the $5^{\text {th }}$ European Conference of the International Federation for Medical and Biological Engineering: How effective is robot therapy?: PARO and people with dementia. (Vol. 37, pp. 784-787). http://dx.roi.org/10.1007/978-3-64223508-5_204

Kayser-Jones, J. \& Schell, E. S. (1997). Staffing and the meal-time experience of long-term care facility residents on a Special Care Unit. American Journal of Alzheimer's Disorder and other Dementias, 12(2), 67-72. http://dx.roi.org/10.1177/153331759701200204

Kayser-Jones, J., Schell, E., Porter, C., \& Paul, S. (1997). Reliability of percentage figures used to record the dietary intake of nursing home residents. Nursing Home Medicine, 5(3), 69-76.

Kehoe, J. (1995). Basic item analysis for multiple-choice tests. Practical Assessment, Research \& Evaluation, 4(10).

Kidd, C. D. \& Breazeal, C. (2008). Proceedings from the International Conference on Intelligent Robots and Systems: Robots at home: Understanding long-term human-robot interaction. (pp. 3230-3235). http://dx.roi.org/10.1109/IROS.2008.4651113

Koshizaki, T. \& Masuda, R. (2010). Proceedings from the International Symposium on Robotics (ISR) and German Conference on Robotics (ROBOTIK): Control of a meal assistance robot capable of using chopsticks. Munich, Germany.

Kuo, I., Rabindran, J. M., Broadbent, E., Lee, Y. I., Kerse, N., Stafford, R. M. Q., \& MacDonald, B. A. (2009). Proceedings from the IEEE International Symposium on Robot and Human Interactive Communication: Age and gender factors in user acceptance of healthcare robots. (pp. 214-219). http://dx.roi.org/10.1109/ROMAN.2009.5326292

Libin, A. \& Cohen-Mansfield, J. (2004). Therapeutic robocat for nursing home residents with dementia: Preliminary inquiry. American Journal of Alzheimer's Disease and Other Dementias, 19(2), 111-116. http://dx.roi.org/10.1177/153331750401900209

Mataric, M., Eriksson, J., Feil-Seifer, D. \& Winstein C. (2007). Socially assistive robotics for post-stroke rehabilitation. International Journal of NeuroEngineering and Rehabilitation, 4(5). http://dx.roi.org/10.1186/1743-0003-4-5 
McColl et al. Meal-Time with a Socially Assistive Robot

Montemerlo, M., Prieau, J., Roy, N., Thrun, S. \& Varma, V. (2002). Proceedings from the AAAI National Conference on Artificial Intelligence: Experiences with a mobile robotics guide for the elderly. (pp. 587-592). http://dx.roi.org/10.1.1.16.7465

Nasreddine Z., Phillips N., Bedirian, V., Charbonneau, S., Whitehead, V., Collin, I., Cummings, J., Chertkow, H. (2005). The Montreal Cognitive Assessment, MoCA: A brief screening tool for mild cognitive impairment. Journal of the American Geriatrics Society, 53(4), 695-699. http://dx.roi.org/10.1111/j.1532-5415.2005.53221.x

Newman, W., \& Cairns, P. (2006). Proceedings from the CSCW Workshop on Collaborating over Paper and Digital Documents: Modelling computer-related disengagement from collaboration in meetings. Banff, AB, Canada

Newman, W., Button, G., \& Cairns, P. (2010). Pauses in doctor-patient conversation during computer use: The design significance of their durations and accompanying topic changes. International journal of human-computer studies, 68(6), 398-409. http://dx.roi.org/10.1016/j.ijhcs.2009.09.001

Ohara, E., Yano, K., Horihata, S., Aoki, T. \& Nishimoto, Y. (2009). Proceedings from the IEEE International Conference on Rehabilitation Robotics (ICORR): Tremor suppression control of Meal-Assist Robot with adaptive filter. (pp. 493-503). http://dx.roi.org/10.1109/ICORR.2009.5209565

Osborn, C. L. \& Marshall, M. (1992). Promoting meal-time independence. Geriatric Nursing, 13(5), 254-256. http://dx.roi.org/10.1016/S0197-4572(05)80414-8

Pokrywka, H. S., Koffler, K. H., Remsburg, R., Bennett, R. G., Roth, J., Tayback, M., \& Wright, J. E. (1997). Accuracy of patient care staff in estimating and documenting meal intake of nursing home residents. Journal of the American Geriatrics Society, 45(10), 1223-1227.

Powers, A., Kiesler, S., Fussell, S. \& Torrey, C. (2007). Proceedings from the ACM/IEEE International Conference on Human-Robot Interaction: Comparing a Computer Agent with a Humanoid Robot. (pp. 145-152). Arlington, Virginia, USA

Rani, P., Sarkar, N., Smith, C. A., \& Kirby, L. D. (2004). Anxiety detecting robotic systemtowards implicit human-robot collaboration. Robotica, 22(1), 85-95. http://dx.roi.org/10.1017/S0263574703005319

Robins, B., Ferrari, E., Dautenhahn, K., Kronreif, G., Prazak-Aram, B., Gelderblom, G., ... Marti, P. (2010). Human-centred design methods: Developing scenarios for robot assisted play informed by user panels and field trials. International Journal of Human-Computer Studies, 68(12), 873898. http://dx.roi.org/10.1016/j.ijhcs.2010.08.001

Schell, E. S. \& Kayser-Jones, J. (1999). The effect of role-taking on caregiver-resident meal-time interaction. Applied Nursing Research, 12(1), 38-44. http://dx.roi.org/10.1016/S08971897(99)80167-0

Sim, K., Yap, G. E., Phua, C., Biswas, J., Phyo Wai, A. A., Tolstikov, A., .. Yap, P. (2010). Proceedings from the IEEE International Conference on e-Health Networking Applications and Services (Healthcom): Improving the accuracy of erroneous-plan recognition system for Activities of Daily Living . (pp. 28-35). http://dx.roi.org/10.1109/HEALTH.2010.5556555

Simmons, S. F., Osterweil, D., \& Schnelle, J. F. (2001). Improving food intake in nursing home residents with feeding assistance: A staffing analysis. The Journals of Gerontology Series A: Biological Sciences and Medical Sciences, 56(12), M790-M794. http://dx.roi.org/10.1093/gerona/56.12.M790

Soyama, R., Ishii, S. \& Fukase, A. (2003). Proceedings from the IEEE International Conference on Rehabilitation Robotics: The development of meal-assistance robot 'My Spoon'. (pp. 88-91). 
Daejeon, Korea

Sullivan D. \& Lipschitz D., (1997). Evaluating and treating nutritional problems in older patients. Clinics in Geriatric Medicine, 13(4), 753-768.

Taggart, W., Turkle, S. \& Kidd, C. D. (2005). Proceedings from Towards Social Mechanisms of Android Science: A COGSCI Workshop, Cognitive Science Society: An interactive robot in a nursing home: Preliminary remarks. Stresa, Italy.

Tapus, A., Tapus, C., \& Mataric, M. J. (2009). Proceedings from the IEEE International Symposium on Robot and Human Interactive Communication: The role of physical embodiment of a therapist robot for individuals with cognitive impairments. (pp. 103-107). http://dx.roi.org/10.1109/ROMAN.2009.5326211

Topping, M. \& Smith, J. (1998). The development of Handy 1, a rehabilitation robotic system to assist the severely disabled. Industrial Robot, 25(5), 316-320. http://dx.roi.org/10.1108/01439919810232459

Tsui, K. M., \& Yanco, H. A. (2009). Proceedings from the Workshop on Good Experimental Methodology in Robotics, Robotics Science and Systems: Towards establishing clinical credibility for rehabilitation and assistive robots through experimental design. Seattle, WA, USA.

Ubeda, A., Azorin, J. M., Garcia, N., Sabater, J. M., \& Perez, C. (2012). Proceedings from the IEEE RAS \& EMBS International Conference on Biomedical Robotics and Biomechatronics (BioRob): Brain-machine interface based on EEG mapping to control an assistive robotic arm. (pp. 1311-1315). http://dx.roi.org/10.1109/BioRob.2012.6290689

Wade, E., Parnandi, A., Mead, R. \& Mataric, M. J. (2011). Socially assistive robotics for guiding motor task practice. Journal of Behavioral Robotics, 2(4), 218-227. http://dx.roi.org/10.2478/s13230-012-0017-0

Wainer, J., Feil-Seifer, D. J., Shell, D. S. \& Mataric, M. J. (2007). Proceedings from the IEEE International Conference on Robot \& Human Interactive Communication: Embodiment and human-robot interaction: A task-based perspective. (pp. 872-877). http://dx.roi.org/10.1109/ROMAN.2007.4415207

Zeisel, J. \& Raia, P. (2000). Nonpharmacological treatment for Alzheimer's disease: A mind-brain approach. American Journal of Alzheimer's Disease and Other Dementias, 15(6), 331-340. http://dx.roi.org/10.1177/153331750001500603

Zhang, T., Kaber, D. Zhu, B., Swangnetr, M., Mosaly, P. \& Hodge, L. (2010). Service robot feature design effects on user perceptions and emotional responses. Intelligent Service Robotics, 3(1), 73-88. http://dx.roi.org/10.1007/s11370-010-0060-9

Authors' names and contact information: D. McColl, derek.mccoll@mail.utoronto.ca and G. Nejat, nejat@mie.utoronto.ca: Autonomous Systems and Biomechatronics Laboratory, Department of Mechanical and Industrial Engineering, University of Toronto, Canada 